\title{
Marcadores prognósticos como um auxílio à conduta clínico-cirúrgica em uma cadela apresentando múltiplos nódulos mamários
}

\author{
Prognostic markers as an aid to the clinical-surgical conduct in a female \\ dog presenting multiple mammary nodes
}

\author{
Daniela de Carvalho Martins ${ }^{1} \&$ Ana Maria Reis Ferreira ${ }^{1}$
}

\begin{abstract}
RESUMO
Os tumores mamários são os tumores mais comumente encontrados em Medicina Veterinária de pequenos animais. A neoplasia mamária em cadelas é um modelo para a carcinogênese mamária humana, e com o comportamento maligno da maioria desses tumores, se faz necessário um diagnóstico rápido e preciso. Este trabalho objetivou utilizar a técnica de imuno-histoquímica como um auxílio ao diagnóstico de múltiplos nódulos mamários retirados através de uma mastectomia radical bilateral em uma cadela sem raça definida (SRD) de 10 anos de idade. As massas tumorais foram fixadas em formol tamponado a 10\% e os anticorpos utilizados foram o anti-tenascina e o anti-fibronectina. As massas apresentaram características histológicas diferentes, sendo classificadas de acordo com a Organização Mundial de Saúde, como adenocarcinoma papilar complexo, adenocarcinoma tubular complexo e carcinossarcoma com alto grau de malignidade e os anticorpos reagiram positivamente. Desta forma, esses marcadores associados são importantes na avaliação do grau de malignidade e do prognóstico dos tumores mamários, como um auxílio ao clínico veterinário.
\end{abstract}

Descritores: tumor mamário canino, tenascina, fibronectina.

\begin{abstract}
The mammary tumours are the more commonly found tumours in Veterinary Medicine of small animals. The mammary neoplasm in bitches is a model for the human mammary carcinogenesis and with the malignant behavior of the most of those tumours, it is done necessary a fast and accurate diagnosis. This study aimed at to use the immunohistochemistry technique as an aid to the diagnosis of the multiple mammary nodes throught a radical bilateral mastectomy in a bitch mixed breed, 10 years old. The tumoural masses were fixed in buffered formalin to $10 \%$ and the antibodies used were the antihuman tenascin and the anti-human fibronectin. The masses presented different histological features, being classified according to the World Health Organization as adenocarcinoma papillary complex, adenocarcinoma tubular complex and carcinosarcoma, with high malignity degree in which the antibodies reacted positively. Then, those associated markers are important in the evaluation of the malignity degree and the prognostic of the mammary tumours, as a aid to the veterinary doctor.
\end{abstract}

Key words: canine mammary tumour, tenascin, fibronectin.

\footnotetext{
${ }^{1}$ Departamento de Patologia, Universidade Federal Fluminense (UFF), Niterói-RJ. CORRESPONDÊNCIA: D. C. Martins [danieladecarvalho@hotmail.com; Fax (21)2558 4147].
} 


\section{INTRODUÇÃO}

A neoplasia mamária na cadela apresenta uma significativa importância na Medicina Veterinária [2], tem sido muito investigada, principalmente por servir de modelo para o estudo do câncer de mama na mulher [5]. Além de possuir uma estreita semelhança com a neoplasia humana [6]. Segundo alguns autores [1,7,8], as neoplasias mamárias em caninos são as neoplasias mais comuns na cadela. O objetivo deste trabalho foi auxiliar através da técnica de imuno-histoquímica a conduta clínico-cirúrgica em uma cadela com múltiplos nódulos mamários.

\section{RELATO DE CASO}

Uma cadela, SRD, de médio porte, com 10 anos de idade, apresentou-se com múltiplos nódulos, de tamanhos variados, consistência firme e distribuídos por toda cadeia mamária, o tratamento empregado foi uma mastectomia radical bilateral. O pós-operatório transcorreu sem alteração. As massas tumorais foram coletadas em formol tamponado a $10 \%$, posteriormente o material foi processado e incluído em parafina para a análise histopatológica de rotina, através da coloração de hematoxilina e eosina (HE). Para análise imuno-histoquímica, o método realizado foi o da estreptavidina biotina peroxidase, sendo utilizados como anticorpos primários o anticorpo monoclonal antiTenascina e o anticorpo policlonal anti-Fibronectina.

\section{RESULTADOS}

Após a histopatologia foi constatado que a técnica cirúrgica realizada apresentou uma margem de segurança bem satisfatória e os tumores mostraram características histológicas diferentes, sendo classificados de acordo com a Organização Mundial de Saúde, como adenocarcinoma papilar complexo, adenocarcinoma tubular complexo (Figura1) e carcinossarcoma. Com relação a técnica de imunohistoquímica, a reação com o anticorpo anti-Tenascina, mostrou uma marcação intensa do estroma em determinadas áreas das amostras tumorais, assim como no endotélio de vasos e também em algumas áreas ao redor dos ductos do tecido mamário, havendo áreas com ausência de marcação (Figura 2). A reação do anticorpo anti-Fibronectina, revelou uma marcação difusa por todo estroma, possuindo também marcação positiva no endotélio de vasos e na membrana basal dos ductos das glândulas (Figura 3).

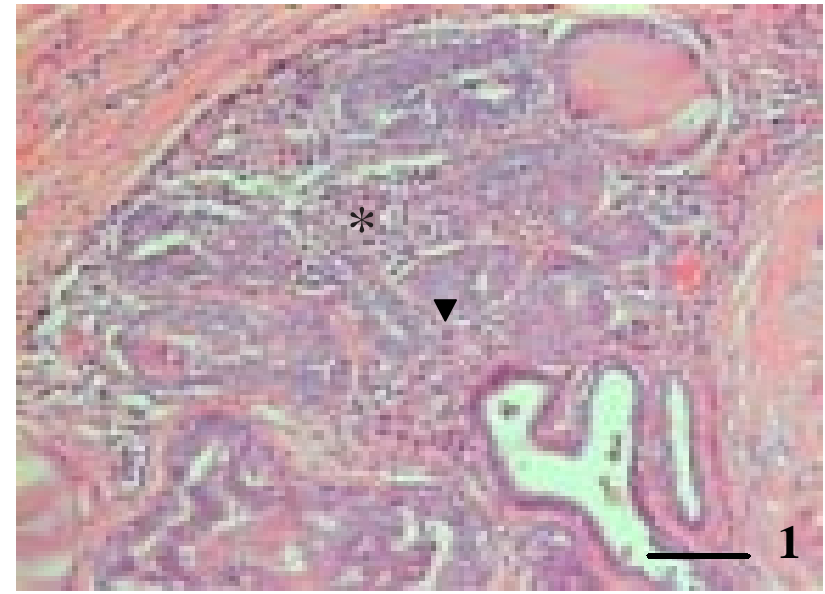

Figura 1. Adenocarcinomatubular complexo mamário canino. Presença de infiltrado inflamatório (asterisco) e núcleos esmerilhados (seta). Coloração hematoxilina-eosina. Barra: 100um.

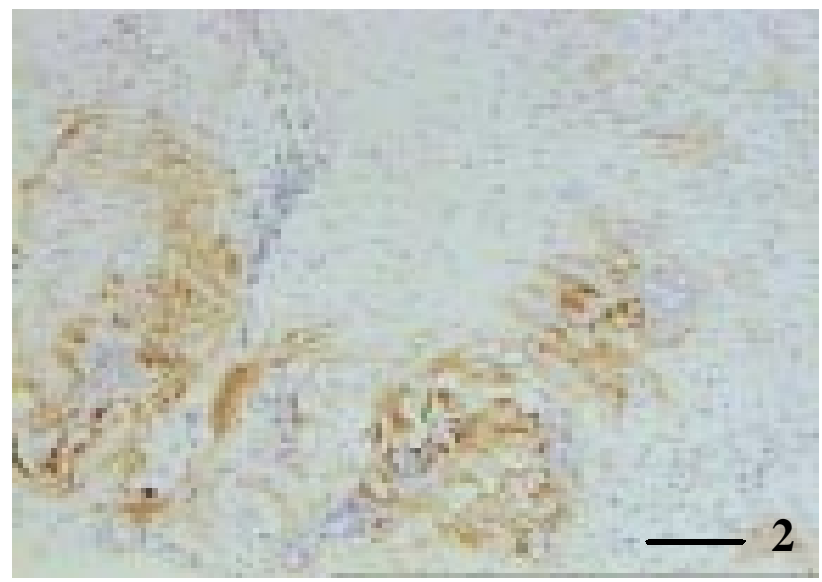

Figura 2. Adenocarcinoma tubular complexo mamário canino. Imunomarcação com o anticorpo anti-Tenascina no estroma, em algumas áreas do tumor, de maneira intensa. Barra: $100 \mu \mathrm{m}$.

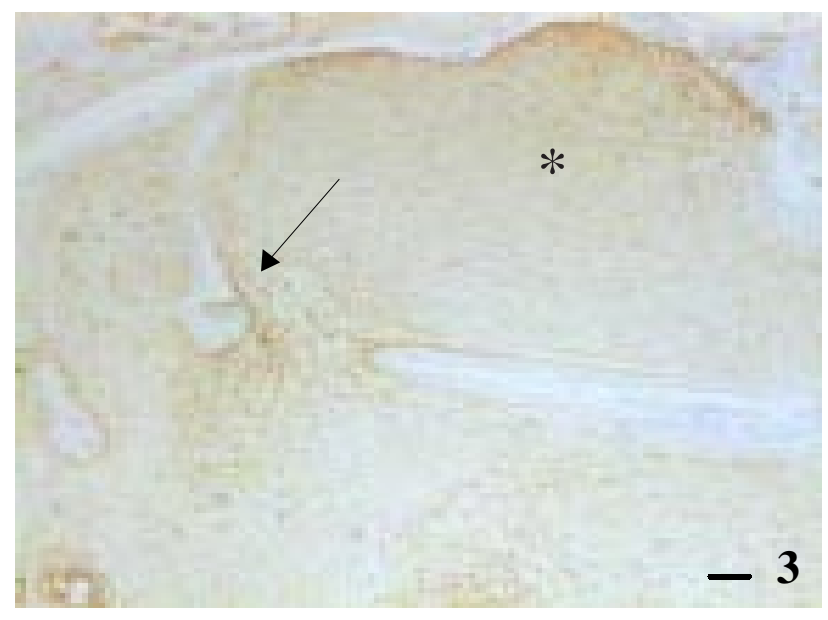

Figura 3. Carcinossarcoma mamário canino. Marcação positiva do anticorpo anti-fibronectina de forma difusa por todo estroma (asterisco) e na membrana basal de ductos glandulares (seta). Barra: $40 \mu \mathrm{m}$. 


\section{DISCUSSÃO}

A marcação da Tenascina encontrada no estroma, foi semelhante à observada por Ishihara et al. [3]. A marcação periglandular está de acordo com a encontrada por Jahkola et al. [4]. A marcação difusa da Fibronectina pelo estroma e a marcação na membrana basal dos ductos das glândulas mamárias foram semelhantes às observadas por Yoshida et al. [9]. Através deste trabalho, identificou-se a expressão da Tenascina e da Fibronectina, que sendo marcadores prognósticos possuem grande importância para os estudos em relação às neoplasias mamárias e suas respectivas metástases, auxiliando desta forma o diagnóstico e o prognóstico tanto para clínico, quanto ao cirurgião.

\section{REFERÊNCIAS}

1 Birchard S.J. \& Sherding R.G. 1994. Saunders Manual of Small Animal Practice. Philadelphia: W.B. Saunders Co., $1467 \mathrm{p}$.

2 Daleck C.R. 1996. Tumor Mamário Canino. Clínica Veterinária. 1: 12-14.

3 Ishihara A., Yoshida T., Tamaki H. \& Sakakura T. 1995. Tenascin expression in cancer cells and stroma of human breast cancer and its prognostic significance. Clinical Cancer Research. 1:1035-1041.

4 Jahkolat T., Toivonen T., von Smitten K., Blomovist C. \& Virtanen I. 1996. Expression of tenascin in invasion border of early breast cancer correlates with higher risk of distant metastasis. Inernational Journal of Cancer (Pred. Oncol.). 69: 445-447.

5 Jubb K.V.F., Kennedy P.C. \& Palmer N. 1993. Pathology of Domestic Animals. 4th edn. San Diego: Academic Press, $780 \mathrm{p}$.

6 Nerurkar V. R., Chitale A. R., Jalnapurkar B. V., Naik S. N. \& Lalitha V. S. 1989. Comparative Pathology of Canine Mammary Tumours. Journal of Comparative Pathology. 101: 389-397.

7 Rostami M., Tateyama S., Uchida K., Naitou H., Yamaguchi R. \& Otsuka H. 1994. Tumors in domestic animals examined during a ten-year period (1980 to 1989) at miyazaki university. Journal of Veterinary Medical Science. 56: 403-405.

8 Withrow S.J. \& Macewen E.G. 1996. Small Animal Clinical Oncology. 2nd edn. Philadelphia: W.B. Saunders Co., 589p.

9 Yoshida T., Matsumoto E., Hanamura N., Kalembeyi I., Katsuta K., Ishihara A. \& Sakakura T. 1997. Co-expression of tenascin and fibronectin in epithelial and stromal cells of benign lesions and ductal carcinomas in the human breast. Journal of Pathology. 182: 421-428. 